\title{
Shaping the agenda of a grand challenge: Institutional mediation of priorities in avian influenza research
}

\author{
Matthew L. Wallace ${ }^{1}$ and Ismael Rafols ${ }^{1,2,3}$ \\ ${ }^{1}$ Ingenio (CSIC-UPV), Universitat Politècnica de València, València, Spain \\ ${ }^{2}$ SPRU (Science Policy Research Unit), University of Sussex, Brighton, England \\ ${ }^{3}$ Observatoire des Sciences et Techniques (OST-HCERES), Paris, France
}

\begin{abstract}
Since outbreaks in 2003, avian influenza has received a considerable amount of funding and become a controversial science policy issue in various respects. Like in many so-called "grand challenges", a variety of perspectives have emerged over how to "tackle" avian influenza and public voices have expressed concern over how research funds are being allocated. In this article we inquire into the priorities of avian influenza research. We use qualitative and quantitative data to examine the relations between societal demands for public science and the existing "research landscape". Interviews of a cross-section of stakeholders revealed a diversity of perspectives on existing research and its desired outcomes, and a generalized difficulty to explicitly connect the two. We also observed a lack of a common understanding of priorities for conducting and applying research. Rather than well-defined research agendas, we found that most public avian influenza research is shaped by three institutional contexts: pharmaceutical industry priorities, publishing and public research funding pressures, and the mandates of international and national science-based policy or public health organizations. Our results are significant for informing not only resource allocation issues, but also a broad perspective of research governance that explicitly takes into account underlying incentive structures when defining priorities.
\end{abstract}

\section{Introduction}

A central question in science policy is how the research system can be mobilized to help tackle grand societal challenges. In particular, research can be mobilized as a part of a broader response to what are broadly viewed as security threats such as climate change, malaria or antibiotic resistance. These challenges involve a range of stakeholders with different understandings and expectations as to what the risk is, what specific solutions should be sought, what role science and technology should play and how research should be configured to address the challenge.

The analysis of these multi-faceted, socio-technical issues is beset by the uncertainty and ambiguity of the problem framings, the difficulty in reconciling the demands (i.e. the outcomes expected from research by policymakers and other stakeholders) with the supply (i.e. the actual and potential outputs of research), and the complexity of linking the relevant areas of knowledge and actors (Sarewitz \& Pielke, 2007, Wallace 
and Rafols, 2015). This is particularly challenging in the public sector, which is beholden not only by financial pressures but also a wide and divergent range of social forces and lobby groups.

The problem of managing research and attributing resources according to societal needs has been so far focused on prioritisation between competing problems. This has been mostly explored in the area of public health. For example, scholarship has explored whether or not the funding for different diseases is commensurate with their burden (Agarwal \& Searls, 2009, pp. 867-869; Evans, Shim, \& loannidis, 2014). However, the literature has yet to explore how research governance has an effect on research prioritisation for (or within) a given challenge - which affects not only how resources are allocated and but also what type of research is conducted (e.g. epidemiology vs. molecular biology).

Public scrutiny over research prioritisation is about demonstrating "value for money", focusing on the "right" priorities, as well as more generally being responsive to public concern over how research is undertaken and used. In this vein, scholars and practitioners have called for more inclusive processes of deliberation (Stirling, 2007b) and for more consideration to debates on research happening both within the scientific community and broader public spheres. We can thus view the research and the research problem itself as being co-constructed by as a scientific and political object through both scientific and political institutions (see, for example, Jasanoff, 2004).

One cannot simply reduce the prioritisation problem to that of funding allocation, since conducting and applying research are processes that depend on various institutional contexts and pressures. These institutions, as structures that influence the behaviour of researchers, policymakers and users of scientific information, play a key role in priority setting, and determine to a large extent the outputs and societal impacts of research produced (Heinze, Shapira, Rogers, \& Senker, 2009; Laudel \& Gläser, 2014). Indeed, science and technology policies aim not only to set funding and priorities, but to have an impact on a broader range of governance options that affect various stages of the research process (Foray, Mowery, \& Nelson, 2012).

In this study we broadly follow Gläser's conceptual framework on the governance of research contents (Gläser, 2012; Laudel and Gläser, 2014): individual researchers "freely" choose research topics (as illustrated by laboratory studies), but their choices are influenced by institutional contexts. The key question then is to understand the links between research governance (as felt by individual researchers via a variety of institutional pressures), research contents and the social outcomes of such research.

In a recent paper, we explored how a "research portfolio" framing of societal challenges might help in fostering a better alignment between science "supply" and societal "demands" (Wallace and Rafols, 2015). In this paper, we empirically investigate how public research resources are mobilised to tackle a grand societal challenge for the case study of avian influenza, and we also study the institutions that govern (in a broad sense) research and shape outcomes. A contribution of this paper is to be one of the few studies so far tentatively linking qualitative investigation on research contents with macro-scale science policy analysis (Laudel and Gläser, 2014). It also intends to bridge the gap between a more social constructivist scholarship that links perceptions of risk (for example, of a pandemic) with a research 
agenda (Jasanoff, 2004; Stirling, 2007b), and a research management or science and innovation policy perspective that seeks practical solutions to administering such "grand societal challenges".

Avian influenza research is found to be a highly contested topic. We first show that there is a widespread difficulty to link specific research avenues with societal outcomes. This is compounded by stakeholders' diverging, value-laden views on both aspects. The lack of a shared understanding is a major obstacle to prioritisation. Rather than strategic research agendas, we find that current institutional dynamics mediates priority setting: pressures arising from the pharmaceutical sector, or associated with publication and obtaining grants, and, to a lesser degree, mandate-driven (governmental or intergovernmental) public organizations are shown to shape what types of avian influenza research is undertaken.

The article is organised as follows. In section 2 we introduce a mixed methods approach which combines interviews and scientometric mapping. In Section 3, we present avian influenza research as the response to a "shock" to the research system. This results not only in an influx of resources, but also in a field that is multi-faceted, multi-stakeholder and associated with various sociotechnical controversies. In Section 4, we explore stakeholder perspectives on avian influenza research covering the following aspects: 1) views of societal demands, i.e., desirable outcomes of avian influenza research; 2) descriptions of the science supply, i.e., the research landscape; and 3) the main institutional contexts that have an effect in the shaping of research contents. Our qualitative interview data are supported by a quantitative analysis of the research landscape and main science policy issues through the mapping of scholarly publications and funding. Section 5 discusses the insights.

\section{Methodology}

Given that it is very problematic to generate or access reliable information on research supply and societal demands for a challenge such as avian flu, we have opted for a mixed methods approach. On the one hand, we relied on funding and publication data to describe research supply. On the other hand, we interviewed informed stakeholders, i.e. scientific experts and policy makers. Informed stakeholders were interviewed in order to a) characterise the landscape of research options, b) link research options to societal outcomes of avian influenza research and make value judgments about research priorities and policy objectives. The approach assumes that there are some common understandings of the risks of avian influenza and the research options to mitigate it.

\subsection{Semi-structured interviews}

A series of semi-structured interviews were conducted to gather a wide variety of perspectives from stakeholders. For this purpose, fourteen interviewees were asked to describe avian influenza research in terms of trends and structure of the field, as well as its outcomes and institutional drivers. The interviewees selected were at relatively senior positions within organizations that were involved in avian influenza research as producers, users or otherwise influential actors regarding the direction of public research. The selection aimed to have candidates from various sectors and countries across Europe. As a starting point for seeking out patterns and characterizing responses, interviewees were classified based on their degree of technical knowledge of any area(s) scientific research related to avian influenza, as well as their degree of policy knowledge or influence, based on their organizational affiliations (see Figure 1). 
Face-to-face interviews took place between February and June of 2014, in the UK, the Netherlands, Belgium, Luxembourg, Spain and Italy, with each interview lasting between one and two and a half hours.

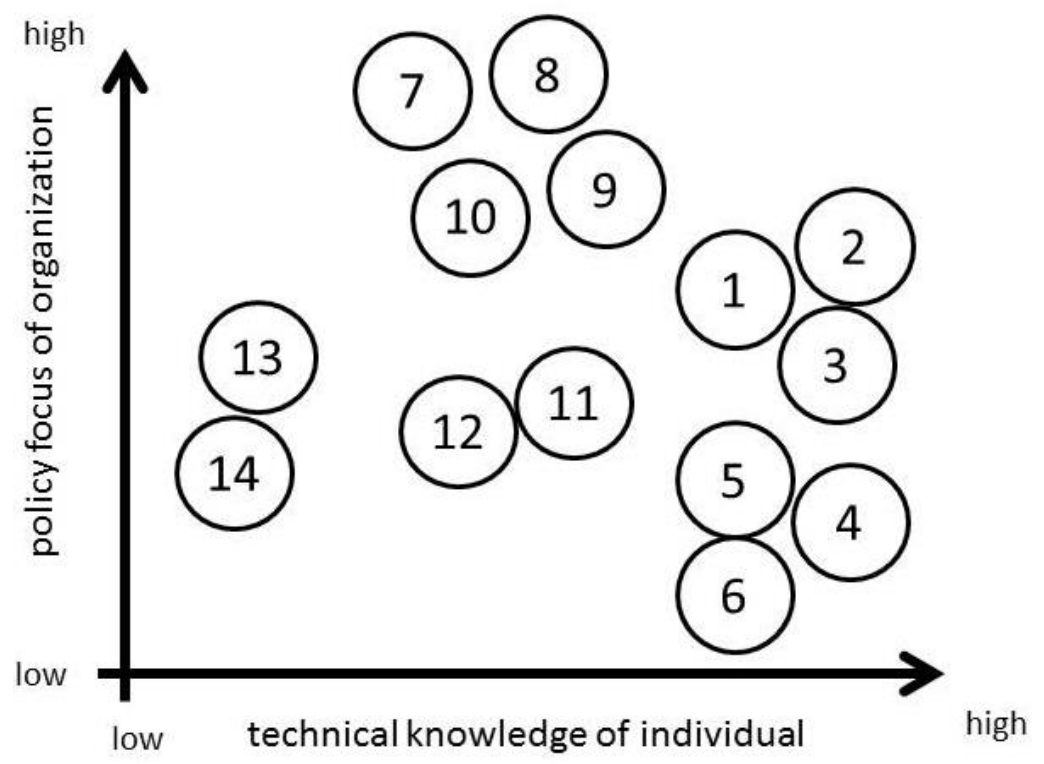

Figure 1. Schematic representation of the distribution of main stakeholders interviewed (arbitrarily assigned a number of 1 to 14 ) according to policy and technical expertise

Participants were asked about their views on various aspects of avian influenza research: what types of research options could be considered, which were prioritised, what obstacles or challenges they faced. We did not intend to make generalizations or statistically significant conclusions about their perspectives on avian influenza research. Rather, the interviews were designed to understand what types of views exist about this field of study and to suggest connections between the type of research conducted and its outcomes. We focused on extracting the context surrounding the account provided by interviewees, on seeking out instances of divergence and consensus among participants, as well as on institutional factors deemed important by researchers (Benner \& Sandström, 2000; Goldfarb, 2008; Heinze et al., 2009; Laudel \& Gläser, 2014).

Through the interviews we obtained views on how the research contents (supply) and outcomes (demands) are related. To do so, we appraised participants' perspectives of the different desirable outcomes and the different research options for achieving them. We also asked participants to discuss institutional factors that affect the interplay between content and outcomes. This approach allowed us to capture narratives and frames associated with different types of avian influenza research, as well as the relationship between institutional drivers and research options, as perceived by participants.

\subsection{Quantitative data mined from funding and publications}

Our analysis was supported by quantitative data on publication on avian influenza over the past 10 years. Delineating a research topic with keywords is difficult and controversial. Our data was obtained by first obtaining the list of all publications pertaining to avian influenza through the Medical Subject Headings (MeSH) of the PubMed system (Rotolo \& Leydesdorff, 2015). Specifically, under the parent heading of 
Influenza A as an organism, we selected specific strains (e.g., H5N1, H7N9), combined with articles tagged as "Influenza in Birds" under the separate parent heading of "Orthomyxoviridae infections". This corpus of articles allowed us to study the research landscape associated with a given set of diseases, as well as to compare it with the research associated more broadly with Influenza A (which includes "swine flu", as well as seasonal influenza strains).

In order to illustrate the diversity and balance of topics and approaches associated with avian influenza, we focused on "mapping" the research landscape as a cognitive space defined by methodologies, theories, disciplinary traditions and different objects of research. While this can be done through several methods such co-citation or bibliometric coupling analyses, we found that maps generated through the network of co-occurrence of terms within the abstracts using the VOSviewer software package, provided a fast and easy-to-use interface so as to identify clusters within the landscape (van Eck \& Waltman, 2010; Waltman, Eck, \& Noyons, 2009).

With maps or "basemaps" formed by all avian influenza publications ( $n=3,700)$ between 2004 and 2013, we overlaid subsets of this dataset in order to visualize only the research associated with specific disciplines (through the classification of journals), research organizations (through the addresses of authors) or funding organizations (through the acknowledgements of funding captured in Web of Science). Specifically, we fixed the locations of the terms found in the basemap, while adjusting the weight assigned to each term based on its occurrence of relative occurrence within a subset. Various settings were used to represent these overlays in order to visualize changes with respect to the basemap. In general, one needs to take care that setting the threshold of most "relevant" terms (which exclude the common terms such as "influenza") and the minimum number of occurrences of a given term, does not change the overall shape of the map. In other words, maps have to be tested for robustness for various settings so as to ascertain that the perspective provided is not an artefact of the choice of parameters.

\section{Background: avian influenza as a case study}

In this section we provide an overview of the avian influenza problem from a science policy perspective. We paint a picture of a research area that underwent a period of tremendous growth in funding worldwide, though dominated by a few major funding and performing research institutions. Over the last 10 years, avian influenza is associated with debates on different types of risk and uncertainty, and that are influential inside and outside the scientific community. This implies a need to consider avian influenza research not only in the broader context of influenza overall, but also in terms of a wide range of policy and stakeholder interests.

\subsection{Global research and policy context of influenza}

Institutional responses to disease and paths to intervention legitimized by scientific knowledge are crafted by perspectives of actors working in the area (Kreimer \& Zabala, 2007). Influenza is simultaneously a scientific, a political and a social object (Quinn, 2008). Historically, influenza has remained elusive to researchers, in large part because of the ability of the virus to mutate, to have varying levels of virulence to spread both through animals and humans. Similarly, preparedness measures or responses to epidemics do not tend to be one-dimensional. A "one size fits all" or purely technocratic response fails to recognize the variety of local conditions and concerns. Also, preparing for a pandemic should recognize the high 
levels of uncertainty associated with influenza and therefore, favour a pluralistic approach (Forster, 2012). Being a global problem, the overall response has been heavily influenced by three international institutions with a focus on human health (the World Health Organization), agriculture and livestock (the Food and Agriculture Organization) and animal health (the International Organization for Animal Health or OIE), under the aegis of a "coevolution" of science and policy (Chien, 2013).

Previous work by lan Scoones has revealed that the three distinct dominant narratives of control are focused on veterinary medicine, public health and pandemic preparedness (Scoones, 2010 Chapter 1). The existence of contending narratives is a source of significant tension in the development of policy. This tension has led to the construction of new worldviews (and programs) such as "One Health", which sought to integrate the animal and human dimensions of influenza. Various framings of risk have arisen due to so-called "pandemic threats" or "emerging diseases", highlighting differences between global preparedness and control measures at the local level. Often, framings of the issue in response to a perceived risk can be characterized by assigning blame to or stigmatizing other (usually less powerful) groups (Abeysinghe \& White, 2011; Barrett \& Brown, 2008; Global Health Watch, 2011, pp. 146-153; King, 2002).

\subsection{Setting the stage: trends in incidence, research funding and public debate}

While all Influenza A strains can in theory be carried by birds, avian influenza usually refers to specific strains which are dominated by birds (as opposed to swine, for example). Furthermore, the bulk of research over the past ten years has tended to focus on highly-pathogenic strains of avian influenza, especially those which may be susceptible to cross-species transmission. In many arenas of policy and research, the term "avian influenza" itself is still closely linked to a perceived risk of the specific H5N1 strain (responsible for most outbreaks since 2003), although the recent emergence of new highlypathogenic strains such as H7N9 has also become a serious concern. Overall, however, there is considerable overlap, both from a policy and research perspective, with other types of influenza.

Table 1 summarizes the number of H5N1 cases and deaths reported since 2003, primarily in Southeast Asia, but also in other countries such as Turkey and Egypt. Another avian influenza strain, H7N9, has infected an estimated 453 people, killing 175 in 2013-14. ${ }^{1}$ To provide some comparison, the 2009-2010 swine influenza pandemic (H1N1) killed at least 18,500 people, based on laboratory-confirmed tests, though the estimate of total deaths is much higher (up to 201,200) (Dawood et al., 2012). While developing countries have advanced, to varying degrees, approaches to tackle the outbreaks within their borders (Scoones, 2010, Chapters 3-6), developed countries have been primarily concerned with dangers of a global pandemic (Abeysinghe \& White, 2011). The swine influenza pandemic of 2009 thus served in part to confirm these fears, while shifting the focus to other strains of influenza such as H1N1.

\footnotetext{
${ }^{1}$ October 2, 2014 WHO risk assessment from

http://www.who.int/influenza/human_animal_interface/influenza_h7n9/Risk_Assessment/en/
} 
Table 1: Number of deaths and reported cases of H5N1 worldwide between 2003 and $2013^{2}$

$\begin{array}{ccc}\text { Year } & \text { H5N1 - reported cases } & \text { H5N1 - deaths } \\ 2003 & 4 & 4 \\ 2004 & 46 & 32 \\ 2005 & 98 & 43 \\ 2006 & 115 & 79 \\ 2007 & 88 & 58 \\ 2008 & 44 & 33 \\ 2009 & 73 & 32 \\ 2010 & 48 & 24 \\ 2011 & 62 & 34 \\ 2012 & 32 & 20 \\ 2013 & 39 & 25\end{array}$

Figure 2 shows the funding profile for avian influenza as a "response" to this crisis, both in absolute dollars and as a proportion of total influenza funding. Figure 3 shows the number of publications associated with Influenza A and avian influenza. The data from the US point a rapid increase in funds, followed by a recent decline, which confirms recent reports from the UK that this was a period in which influenza research in general grew significantly, especially considering its "burden" relative to other diseases (Head et al., 2014). Furthermore, while avian influenza dominated the influenza A research landscape prior to 2009, the emergence of the swine influenza pandemic shifted research priorities significantly. Thus, beyond the increases in inputs and outputs, these patterns point to the need to understand how research systemsin particular, dominant institutions-responded to a large "shock" (and influx of funding) in 2003-04, followed by another one in 2009.

\footnotetext{
2 July 27, 2014 data taken from the WHO at http://www.who.int/influenza/human_animal_interface/H5N1_cumulative_table_archives/en/
} 


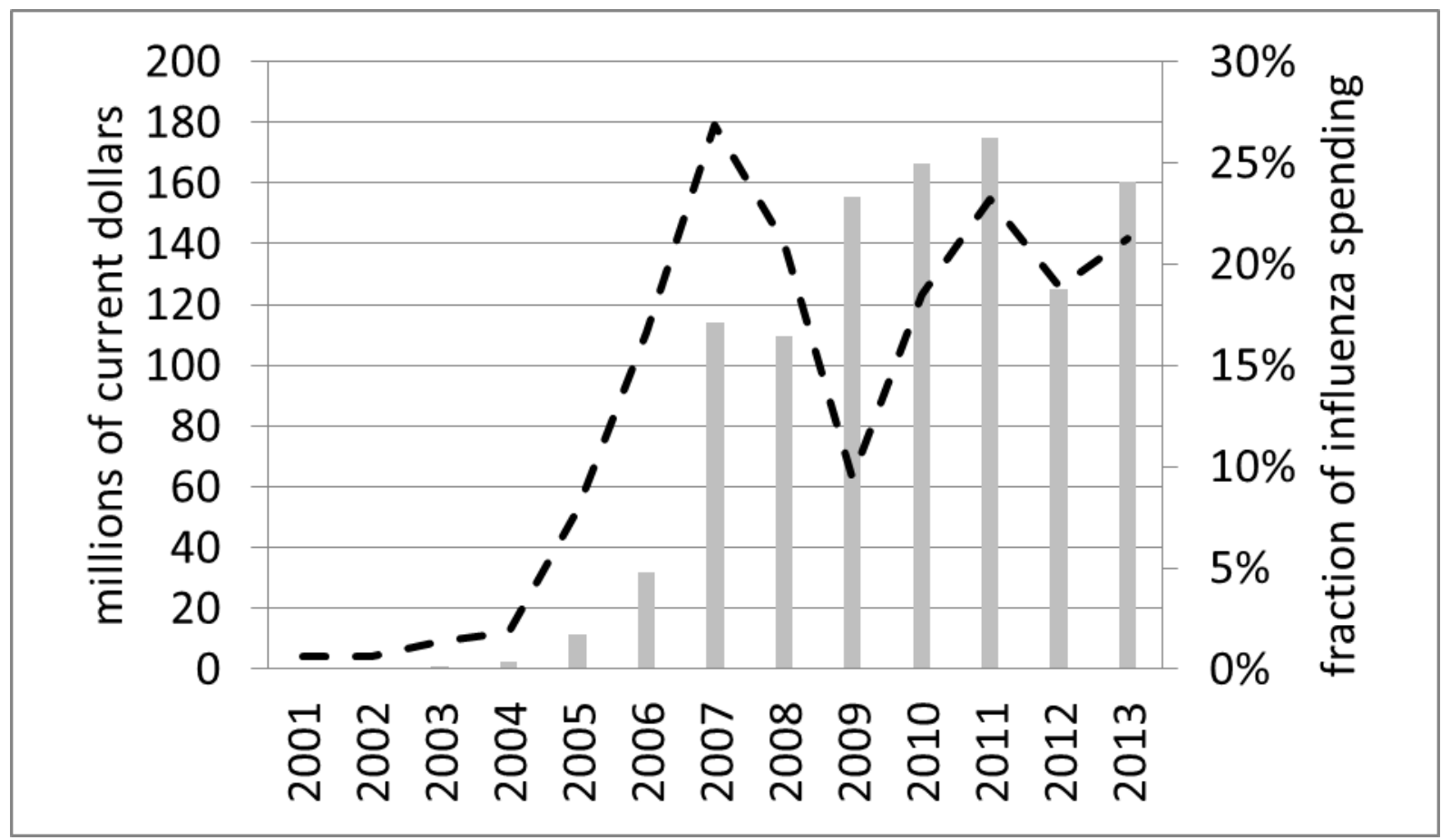

Figure 2. Vertical bars: NIH funding (in millions of dollars) for avian influenza, by fiscal year. Dotted line: avian funding expressed as a fraction of total spending on influenza, including H1N1. ${ }^{3}$

${ }^{3}$ Data downloaded using NIH RePORTER tool (http://report.nih.gov/), June 2014, using keywords pertaining to influenza overall and strains typically associated with "avian influenza" (H5N1, H7N9). Both project and sub-project funding is included. 


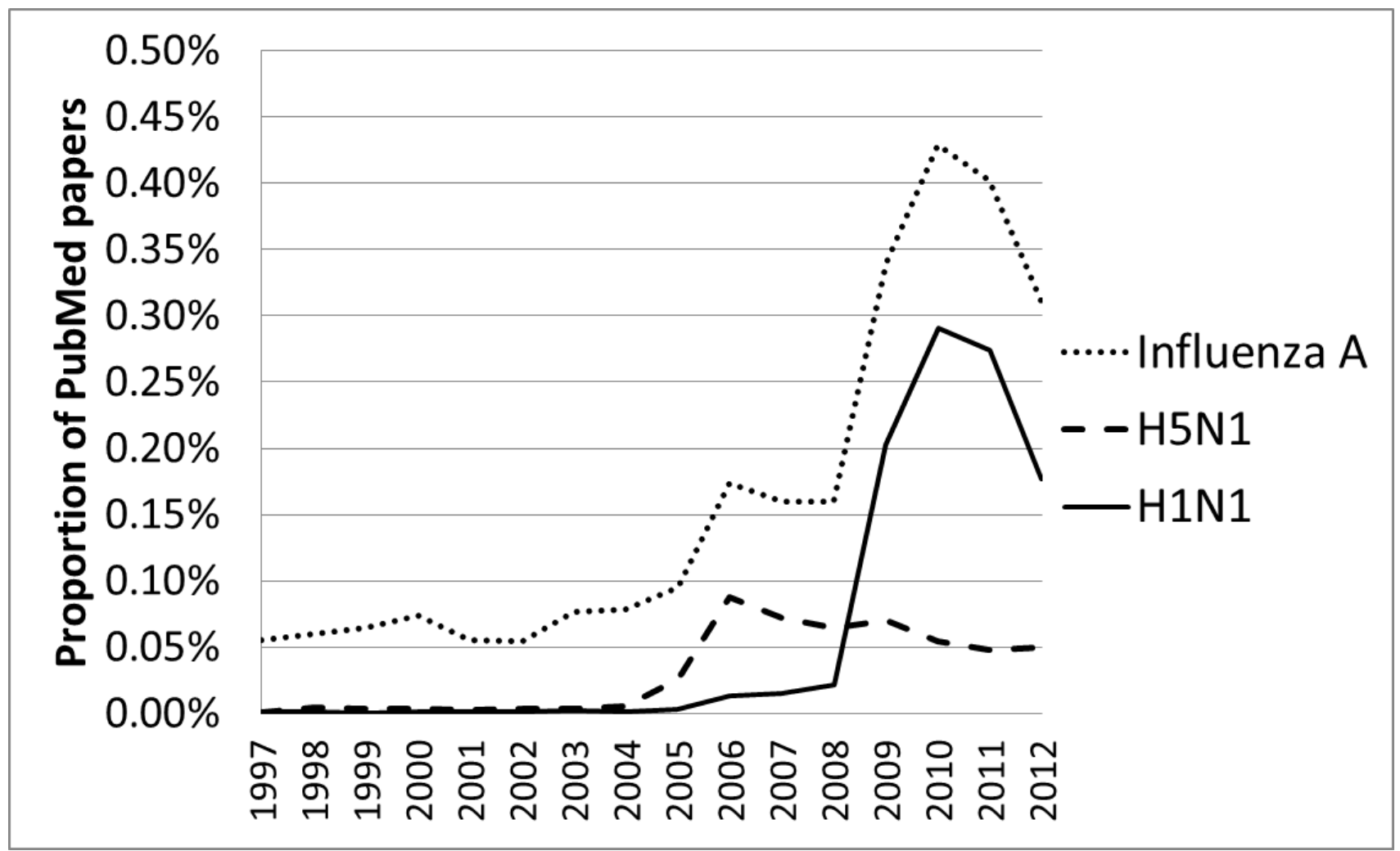

Figure 3. Number of papers published on two major strains of Influenza A. H5N1 is the strain most commonly associated with avian influenza.

There are a variety of science policy debates when there is a rapid increase in research on a contentious, high-profile issue. These debates can be in part captured through discussions in prominent scientific journals (Waaijer, van Bochove, \& van Eck, 2011). We performed a search for editorials related to avian influenza ${ }^{4}$ in Science, Nature, The Lancet, British Medical Journal, New England Journal of Medicine and the Proceedings of the National Academies of Science and apply an ad hoc classification (acknowledging significant overlap) of the 84 editorials found. "Vaccine and treatment" refers to the pharmaceutical methods to mitigating risk (in particular, the debate over their effectiveness or equitable access); "characterization" refers to debates over the nature and origins of the disease; "dual-use research" refers to the risk associated with gain-of-function experiments for bioterrorism or inadvertent escape of the virus; "control" refers to debates over the most effective strategies for mitigating risk (on a national or global scale); and "pandemic risk" refers to the debate over estimating the risk of a global pandemic.

Figure 4 summarizes the evolution of these topics, indicating the waxing and waning of various debates. Initial debates focused on defining risk, while later debates tended to focus on dangers of "advanced" research (2012), or characterization and control of new strains (2012-2013). Our cursory examination of editorials points to a variety of sociotechnical framings of the research itself, which go beyond a technocratic approach to risk management (Slovic, 1993). While some of these themes are focused on the

\footnotetext{
${ }^{4}$ Here, we searched for the terms "avian flu", "avian influenza", "bird flu", H5N1 and H7N9 in these journals and restrict ourselves to the "editorial material" category of articles in Web of Knowledge.
} 
uses of research (e.g., vaccines and treatment), others pertain more to the content of research (e.g., the characterization or avian influenza) and a significant number of debates speak to both of these elements. The controversies point to an engagement of policymakers, researchers and the public in defining (or seeking to define) the research agenda, especially as it pertains to risk mitigation. Indeed, our interviews revealed strong opinions among almost all stakeholders that "research funds are not addressing the right priorities". The following sections of this paper aims not to assess whether this is empirically "true", but to characterize such a disconnect or, more generally, the difficulties in linking research with outcomes.

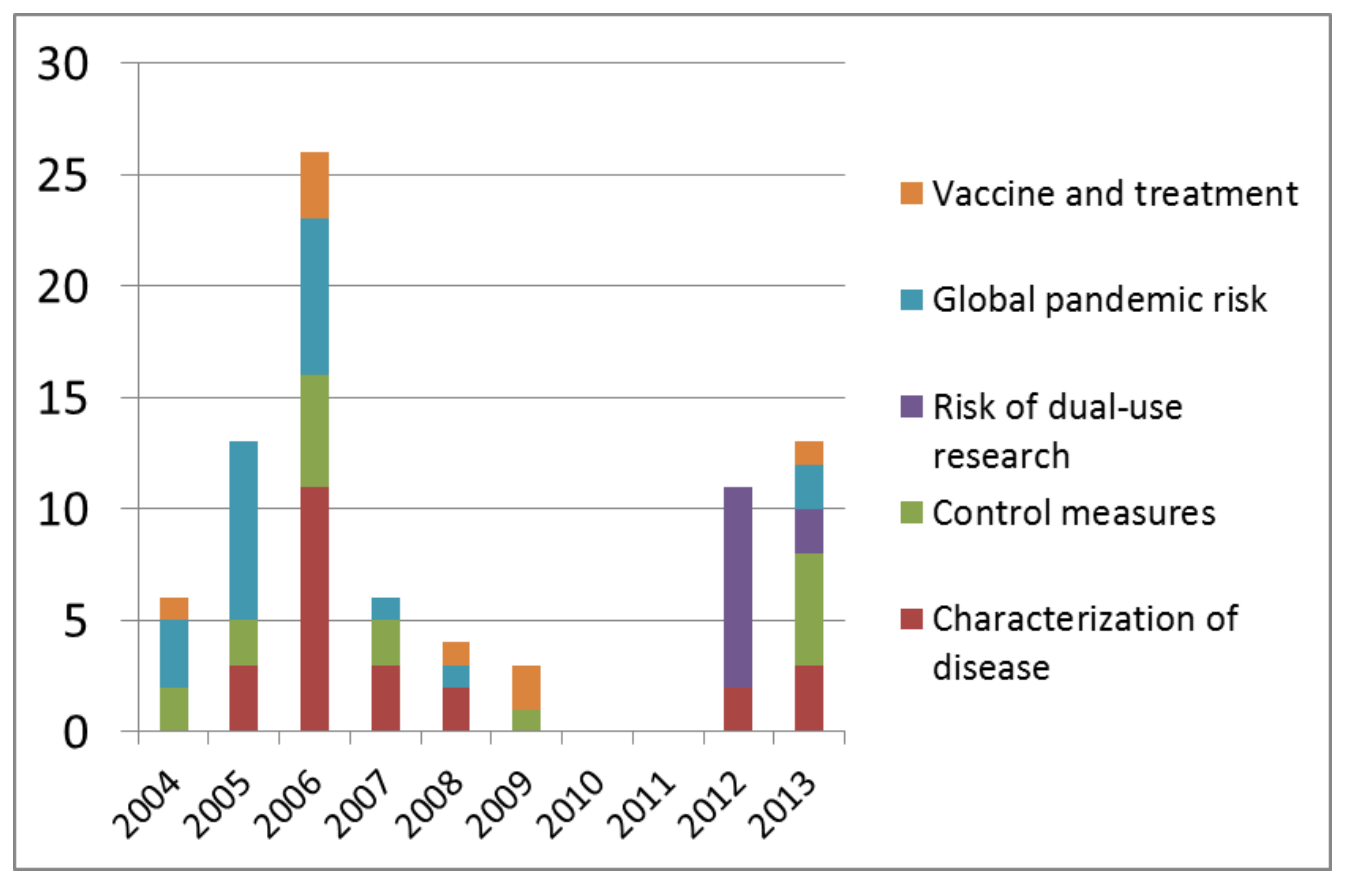

Figure 4: Number of editorials regarding avian influenza in leading scientific journals, manually assigned to five different categories.

\section{Results: Perceptions of societal demands, research supply and the mediating role of institutions}

\subsection{Demand: diverging views on desirable societal outcomes}

This section explores the challenges in linking research and outcomes by focusing on the latter. We first begin by describing the diversity of stakeholders' perceptions of how the risk of an avian influenza pandemic can be mitigated by research. We then explore the challenges associated with articulating specific pathways to outcomes.

\subsubsection{Narratives of risk}

Risk framings play a dominant role in how the overall context of avian influenza control, including research, is perceived. These perspectives speak primarily to the way risk is viewed within a given institutional context (Kasperson et al., 1988). Figure 5 highlights the existence of diverse frames, heterogeneous perspectives and lack of consensus regarding risk. These differences exist even within the same type of stakeholders. We can summarize perceptions of risk in three different ways. The first 
concerns the level of uncertainty associated with a future epidemic, e.g. whether one believes that a pandemic similar to that of 1918 is likely to occur or not. The second deals with a normative vision of risk assessment processes and whether the pandemic "threat" can be best addressed through formal, standardized mechanisms (generally by larger organizations) or through a more subjective, informal procedure (generally in smaller field or lab-based settings). For example:

The zoonotic risk. Not in a formal way. [...] In a, sort of, "God, this looks bloody dangerous," or "This one looks about the same as," such and such. [...] It's a gamble. But, you know, what you're trying to do is you've got to have - you can't do it by sticking things into computer programs. It's sort of like a general feel for things that - I think it's a general feel (government researcher).
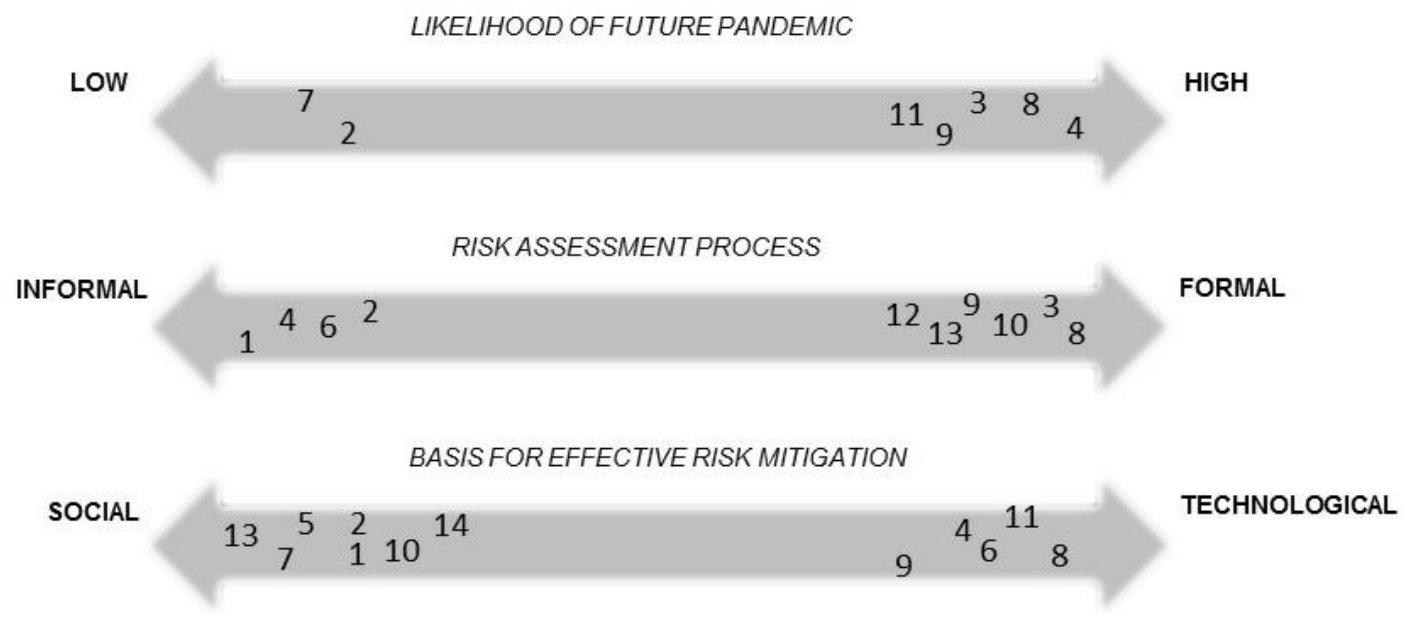

Figure 5. A schematic representation of the three axis according to which we describe perceptions of risk and risk mitigation. The numbers refer to individual interviewed stakeholders (see Figure 1). Note that many stakeholders did not express a specific preference along some of the axes, hence not all interviewees are represented. No strong correlation was found with interviewees' expertise, as represented in the two axes of Figure 1.

The situation is further complicated by the fact that many recognize the possibility of adverse outcomes of research. In the case of avian influenza, the most well-known is dual-use research, commonly associated with "gain-of-function" experiments, whereby viruses undergo mutations in a laboratory setting (for example, Herfst et al., 2012), leading to, some argue, a safety risk for the general public. Since 2011, this has been an object of intense technical, ethical and policy debate, with significant implications for the governance of research (Edwards, Revill, \& Bezuidenhout, 2014; Suk, Bartels, Broberg, Struelens, \& Ozin, 2014). Others hinted at control measures arising from flu research that might have an unacceptably adverse effect on livelihoods. These findings point to the need to recognize a broad range of uncertainties associated with research itself.

The narratives put forth by stakeholders point to a plurality of fundamentally different views on risk and its management or mitigation. Beyond the well-documented conceptual and institutional gaps between scientists and policymakers, or between how the public and "experts" perceive risk, our results highlight that there are diverging fundamental framings of risk, which are heavily influenced by an individual's 
background and institutional context. How a researcher views the main challenges associated with avian influenza in turn has an impact on perceptions of specific pathways to solutions.

\subsubsection{Pathways from research to solutions}

Next we characterize the normative views of stakeholders as preferring a "top-down" or "bottom-up" approach for risk mitigation strategies (see Figure 5). In general, top-down approaches speak to technological solutions which are centrally deployed (internationally or by country), while bottom-up solutions are more associated with solutions which take into account the local socio-economic conditions. The analysis of the interviews suggests that those with high levels of technical knowledge tend to view "bottom-up" expertise as a good means to gauge risk and inform public health policy. However, the frames favoured by stakeholders are not primarily based on the level of technical knowledge or on the level of involvement with policy.

Another critical issue for stakeholders is where the science policy decisions are made or, alternately, where the onus lies for decision-making regarding the allocation of resources for research. In comparison to other public health issues, or even other infectious diseases (e.g., HIV, malaria), influenza research funding is not seen as an area where a wide range of stakeholders can or should participate in decisionmaking. This lack of engagement in science policy results in more influence over research by incumbent assumptions and institutional norms. Specifically, scientists or research managers view the decisions as "purely political", while those involved in health policy view the decisions as "purely technical". For example, when discussing vaccines:

If we would have vaccines, which are prepared and tested, then we would be in a better situation for protection, just in case. But that's a political and a governmental decision. It's not a technical purpose (researcher)

[vaccine development efforts] are moving a bit too slow, which might be related to a number of factors including technical and scientific factors, but maybe related in the fact that there are not enough funds to allow such enterprises and such ideas to move forward. (policymaker).

Stakeholders both within and beyond the research community found it difficult, and sometimes impossible, to articulate specific pathways from research agendas to solutions. While there is general agreement on the need to "tackle" avian influenza or to "guard against" future epidemics, any steps towards these general outcomes were usually not framed via a pathways fostered by specific research goals. While many shared a taxonomy of possible mitigation strategies as either antiviral drugs, vaccines or non-pharmaceutical interventions, such distinctions are subjective, not unanimous and do not lead to the articulation of specific priorities (Ferguson et al., 2006). This includes, for example, whether we should focus on improving existing influenza vaccines or on developing new ones, and how this related to problems of access to, as well as distribution and production of vaccines (Fidler, 2010; Friede et al., 2011). In the case of non-technological pathways (e.g., focusing on primary care, socioeconomics or national surveillance) for addressing avian influenza, the gap between research and identifiable outcomes often appears even wider. 


\subsection{Supply: redefining the avian influenza research landscape}

A second difficulty in setting priorities is associated with a lack of common understanding of the research options. Interviews revealed an unexpected disagreement regarding possible research areas of themes associated with avian influenza. As we explain in this section, not only is the division of research into cognitive categories (distinct bodies of knowledge) ambiguous, but there are inherently divergent worldviews as to what constitute "promising" areas of research.

\subsubsection{Characterizing distinct research options}

Even though disciplinary norms and perspectives are well-entrenched in the scientific communities and thus remain dominant (Becher \& Trowler, 2001; Bourdieu, 1976), many societal challenges are increasingly viewed as requiring multi- or inter-disciplinary approaches. This means that the knowledge base for societal challenges can be expected to draw upon various disciplinary areas. Therefore, the integration of a broad spectrum of cognitive perspectives is often cited as a desirable to tackle "complex problems" such as avian influenza (Rosenfield, 1992). Stakeholders interviewed generally agreed that there is a need for diverse research avenues that transcend traditional disciplinary divisions.

To illustrate this diversity, we develop a semantic map of avian influenza research (Figure 6) based on terms found in abstracts of scientific articles between 2004 and 2013 using the VOSViewer software. The vocabulary provides us with a sense of what type of methods and objects dominate a given area of research (see caption of Figure 6). Interestingly, the clusters cannot be easily characterized with disciplinary labels. In particular, our interviews called into question simple interpretations of terms such as "virology", "immunology" and "epidemiology", which are commonly associated with specific types of research. Both the identification of the main fields and the language used to describe these fields varied widely among participants.

As seen in Figure 6 below, the boundaries between different conventional disciplinary fields are fluid, in part because research objects and methodologies are not specific to a single discipline. More importantly, certain areas of research were found to be associated with extremely different types of outcomes. For example, some viewed animal research as primarily focused on understanding zoonosis, while others associated it mainly with control measures. Similarly, some associated epidemiological modelling with means for understanding the disease at early stages, while others viewed it as a source of policy recommendations for controlling outbreaks.

Furthermore, we observed that seemingly "objective" labels of research areas often came with judgments regarding the utility or the rigour associated with them. For example, that which is closely associated with public health or tracking epidemics was criticized by some as "soft", more "routine" or lacking analytical rigour, whereas research associated with the virus or immune response was described by others as "detached" from the main problems or as "too expensive" for what it yields. As such, some public research in a given area such as immunology was sometimes described as either over-funded in relation to the insights gained, while other research areas such as animal-based epidemiology were sometimes seen as under-funded. Modelling in virology, as in epidemiology, for example, was an area of particular contention, as described by a scientist working primarily in a policy arena: 
There's a lot of research going on in modeling. You know, modeling diseases? But I always put some question marks. It's often difficult to model reality. There are too many unknowns and uncertainties. The danger is if you present a policymaker with a nice model with curves moving round and things, they tend to kind of adhere to it like, "Oh, great. This is kind of a solution for me."

Participants did not view individual research areas as separate alternative options for tackling influenza research, preferring to consider various combinations of disparate fields of research. Indeed, research portfolios of programmes or organisations are thus characterized by varying proportions of resources being devoted to different types of research.

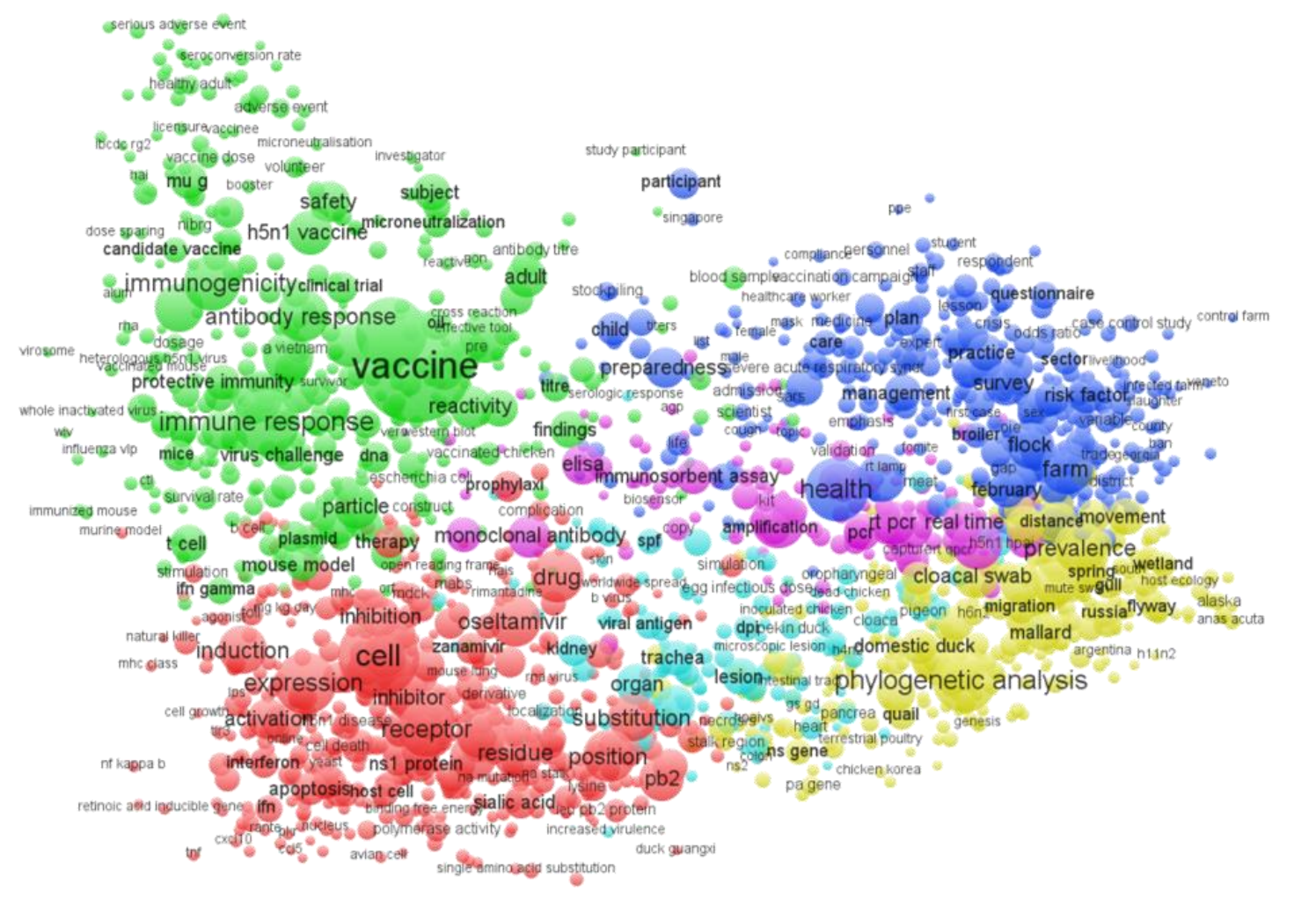

Figure 6. Map of the research landscape of avian influenza. The colours denote various clusters found through VOSViewer's clustering algorithm, while the proximity denotes the level of co-occurrence of the terms. Here, only terms among the $60 \%$ most "relevant" (i.e., allowing to distinguish between clusters) and appearing at least 6 times are kept (see details in Methods section). Based on the terms alone, the top left corresponds to work related to vaccine development and understanding the immune system; the bottom left focuses on the virological processes and on drug development; the top right is related to epidemiology and pandemic preparedness; the bottom right on characterizing the virus origins and spread; and clusters in the middle are related to detection and diagnosis. An interactive version of the map can be found here [hyperlink to be added]. 

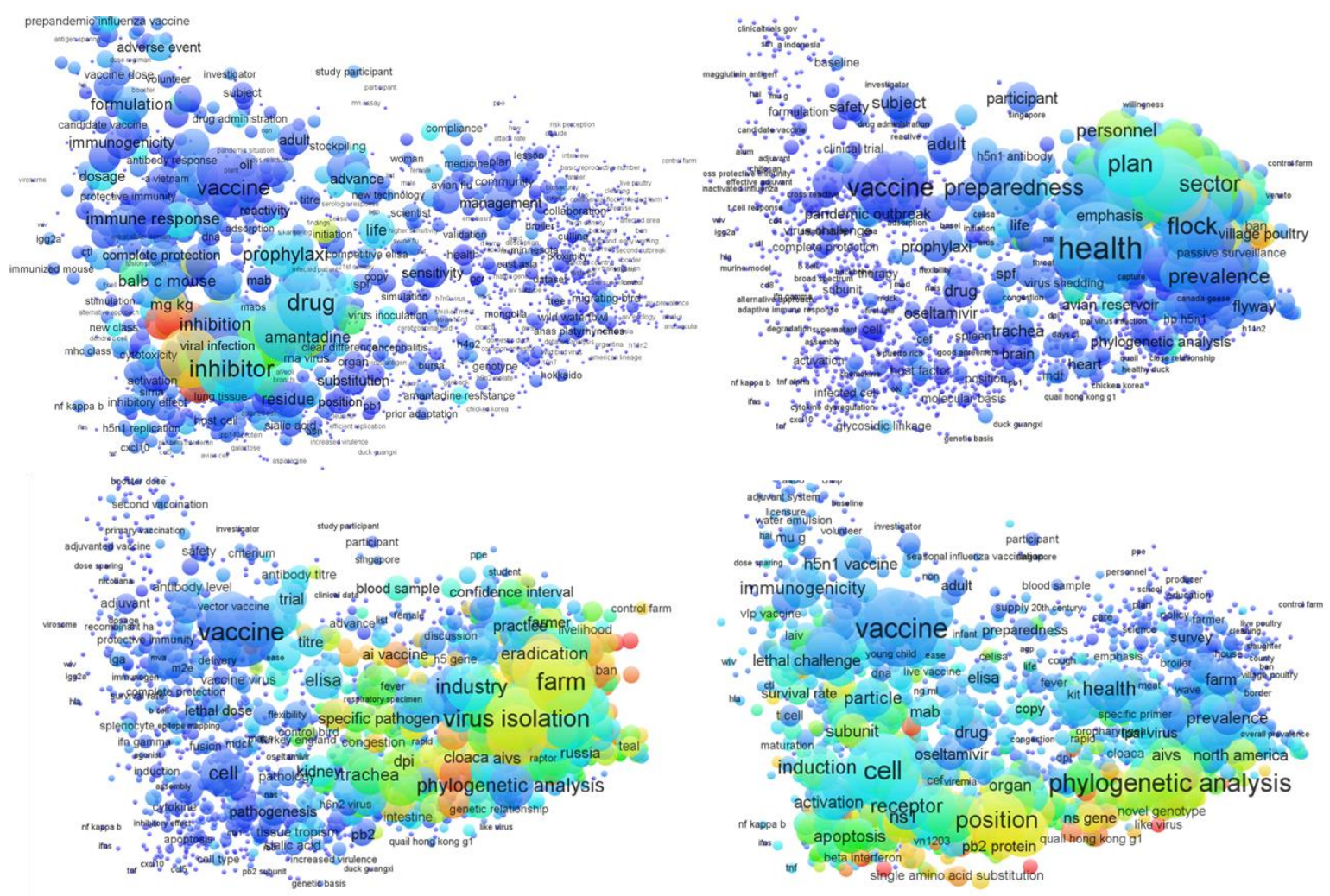

Figure 7. "Heat map" overlay of Figure 6 highlighting the concentration of different terms (yellow and red indicate higher frequency). It shows the prevalence of terms within the areas associated with specific Web of Knowledge subject categories, as defined by a set of journals. Clockwise, from the top left: "Pharmacology and Pharmacy", "Public, environmental and occupational health" / "Health care sciences and services", "Virology" and "Veterinary medicine". The size of circles represents the absolute frequency of occurrence of terms in abstracts found in these subject categories. The colour scale (blue to red) indicates the relative occurrence of these terms, compared with the basemap, thus highlighting terms that are very specific to a given subject category.

Perspectives on research "worldviews"

We focus here on overall views of the research landscape, not just its constituent parts. Each participant presented their own distinct view of it. Those with greater technical knowledge provided a more detailed view, though often of a more limited scope, than those who are more associated with the policy side of avian influenza. Specifically, whether heavily involved in the research enterprise or viewing it from a users' perspective, stakeholders usually described avian influenza research overall in terms of two (sometimes three) basic, but diverging, approaches. Often such dichotomies contain implicit or explicit judgments (i.e., one approach is seen as "more desirable" than the other).

Participants generally divided the overall research landscape in one of four different ways: 1) basic vs. applied research; 2) laboratory vs. field research; 3) animal vs. human-oriented research; and 4) laboratory vs. clinical research. Indeed, if we examine Figure 6 in closer detail, the map can be divided in two parts along any of these lines. Indeed, Figure 7 illustrates these various divisions, using Web of Science subject categories, to show how topics or disciplines - in this example, public health, pharmacology, veterinary science and virology - define various polarized landscapes with "blurry" boundaries. Rarely was 
a simple of division of "basic" vs. "applied" research invoked by stakeholders, despite the fact that many science institutions (including funders) still rely on this dichotomy (Calvert, 2006).

These multiple "polarities" preclude the existence of any universal means of decomposing the research landscape into a set of "value-free" categories. Indeed, the research gaps that stakeholders identified in research are directly related to how they viewed different fields in terms of being more related or similar to each other, or how they saw the scientific community separated in two camps at the national or international level. Coupled with the diverging views on risk mitigation as research outcomes as impediments to research prioritisation, the question is then what institutional factors drive the research agenda and how.

\subsection{Incentives and institutions that drive the research agenda}

While stakeholders perceived the landscape and outcomes of research differently, they generally agreed in finding that, despite significant investments in the past decade, public research is to varying degrees "misaligned" with public health priorities for avian influenza. Participants also agreed that "good" research needed to be able to quickly adapt to avian influenza epidemics and that there are significant benefits to pursuing different approaches and increasing linkages between disparate areas of research (on all scales). Most importantly, participants agreed that various institutions play a role in preventing research from most "effectively" contributing to outcomes, or that these institutions could somehow "do a better job" (e.g., through new coordination measures) at promoting higher quality and more useful research in this area. Thus, achieving "better" alignment was seen not just about allocating funding but about improving the management, performance and use research on avian influenza.

Therefore, in this section we explore how dominant institutions associated with the public research system can shape research agendas that foster or hinder alignment between "supply" and "demand". In particular, three categories of pressures were identified by the narratives and normative opinions of stakeholders: financial incentives from the private sector, the academic reward system (including both funding and publishing), and explicit missions of national or international science-based organizations. Each interviewee's perception of the (negative) influence of these pressures was ranked by our analysis as low, medium, high or not addressed (see Table 2), and associated either with research in general or with specific areas such as epidemiology or vaccine development. The following sections analyze this data and explore the contexts for these statements.

Table 2: Number of interviewees expressing various levels of influence from categories of institutions on research. Numbers in parentheses indicate subset relating only to a specific area of research (e.g., vaccine development) rather than the entire landscape. There is no strong correlation between the views on institutions and the nature of the stakeholders or their respective organizations (Figure 1).

\begin{tabular}{|c|c|c|c|c|}
\hline Institution & High influence & $\begin{array}{c}\text { Medium } \\
\text { influence }\end{array}$ & Low influence & Not specified \\
\hline Pharmaceutical industry & $6(3)$ & 4 & 3 & 1 \\
\hline
\end{tabular}




\begin{tabular}{|c|c|c|c|c|c|}
\hline \multirow{2}{*}{$\begin{array}{c}\text { Academic } \\
\text { reward } \\
\text { system }\end{array}$} & $\begin{array}{c}\text { Scholarly } \\
\text { publishing }\end{array}$ & $6(2)$ & 3 & 1 & 4 \\
\cline { 2 - 5 } & $\begin{array}{c}\text { Funding } \\
\text { incentives }\end{array}$ & $4(3)$ & $4(1)$ & 2 & 4 \\
\hline \multicolumn{2}{|c|}{ Organisational missions } & 5 & 4 & 0 & 5 \\
\hline
\end{tabular}

\subsubsection{Financial incentives and private sector influence}

The private sector, primarily through the development of vaccines and antiviral drugs, plays a key role in the avian influenza research landscape. Many participants viewed the pharmaceutical industries as driving innovation and as the main pathway to mitigating the risk of a pandemic outbreak. They cited the fact that the larger financial investments from the private sector have a strong effect on how public research is undertaken, beyond bringing to market pharmaceutical products. For example, there are strong incentives engage in public-private partnerships or to supplement public with private funding, across a range of areas of influenza funding. This is manifest in how research policies (e.g., calls for proposals) are set by public entities, for example.

Almost half of participants felt there is a strong (often seen as negative) influence from the private sector on public research. This view does not appear to be correlated with technical or policy "expertise", but rather with an interviewee's values or the stated missions of their respective organizations. Many participants also felt that the focus of the pharmaceutical industry, with a need to ensure good financial returns, is too narrow and that this affects the breadth of areas considered by public researchers. For example, some interviewees questioned the industry focus on antivirals, since one-time vaccines usually have the potential to generate less revenue than antivirals in the case of an epidemic, but they may in fact have a stronger impact on mortality and infection (Ferguson et al., 2006).

Figure 8 illustrates where the focus of private sector support lies in the overall research landscape. Although insights are limited, it shows the focus on vaccines and antivirals mentioned, and a potential lack of diversity when considering the multitude of perspectives on risk and risk mitigation. This focus is likely to support a "lock-in" of solutions based on revenue-generating pharmaceuticals, precluding a diversity of options implicit in the broader sociotechnical debates (Stirling, 2007a). Specifically, this tends to inhibit focused efforts non-pharmaceutical interventions or vaccine-based pathways less valuable from a market perspective. One researcher operating in the policy arena summarized the situation as follows:

Now, very few studies, by the way, are being done in the last 20 years to look at trying to answer that question [what causes acute respiratory illnesses]. And this will not surprise you because there is very little money in these studies because they might turn up answers that you do not want.

Overall, real or perceived influence from the pharmaceutical industry as a key institution in avian influenza research has increased tensions within the community of researchers and policymakers (especially regulators). It has had an indirect impact on public science through the prospect of real or perceived 
conflicts of interest faced by researchers in such a highly politicized field, be it due to these conflicts affecting the conduct of public science or due to the barriers against them which prevent effective intersectoral collaborations and access to private sector funding (Gulbrandsen \& Smeby, 2005). The recent controversy over the effectiveness of the antiviral Tamiflu and the availability of data from clinical trials

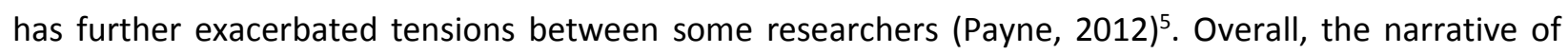
negative influence of the pharmaceutical industry on public research is relatively pervasive, though the mechanisms of this influence are rarely articulated in a specific manner. Furthermore, its influence over the research landscape extends not only to the pharmaceutical vs. non-pharmaceutical approaches, but also to choices of different pharmaceutical pathways to mitigate the risk of a pandemic.

${ }^{5}$ For more details on the correspondence between various parties, see: http://www.bmj.com/tamiflu/roche. 

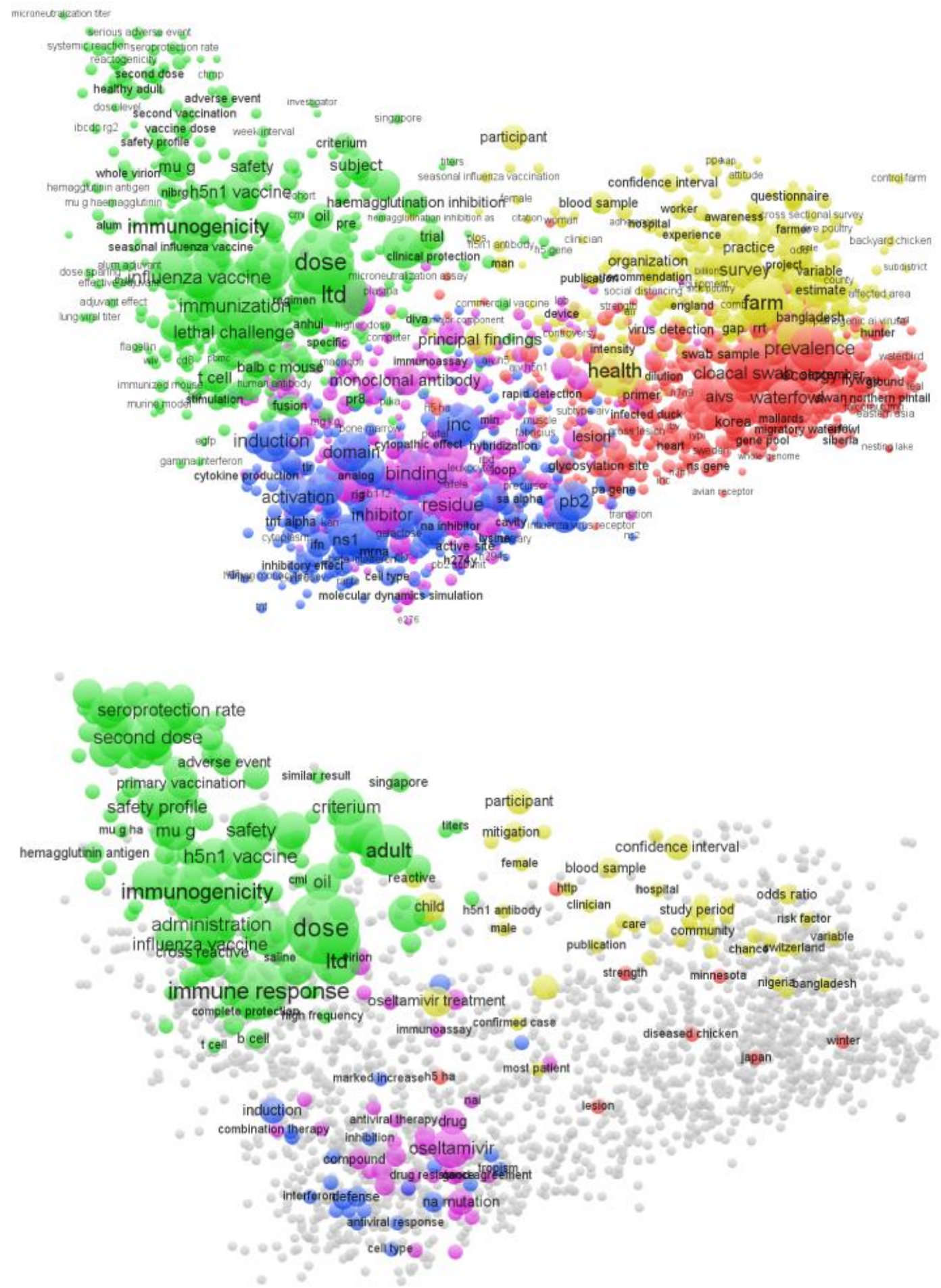

Figure 8. Top: Entire avian influenza research landscape (2009-13). The period is selected based on the availability of funding acknowledgment data from Web of Knowledge. Groupings similar to the 2004-13 case presented in Figure 6 are observed (clockwise, from top left, we find clusters related to vaccine development, epidemiology, veterinary science and virology). Bottom: overlay restricting terms to those appearing in articles acknowledging funding from the four most prevalent pharmaceutical companies: GlaxoSmithKline, Hoffmann - La Roche, Novartis and Sanofi Pasteur. 


\subsubsection{The academic reward system: publishing and funding}

Most participants believed that decisions regarding publication of results and regarding the allocation of funding played an important role in shaping avian influenza research. Grants and publications are the two main "currencies" of university research and how they are structured has a well-documented impact on the research enterprise itself (Butler, 2003). Most participants negatively viewed these pressures, since they lead to certain fields of research being favoured over others in terms of funding and reputation. We separated the reward mechanisms into two systems: the public funding system and the publishing system.

For scientists, obtaining external research funding is not only a means for acquiring research resources, but also a means to gain reputation that is part of the performance assessment, even though it is not necessarily a good gauge of quality (Laudel, 2005). A recent (perceived) drop in funding for avian influenza (see Figure 2) was raised by several interviewees as having exacerbated the competition for resources. Some participants explained that funding schemes favoured fields such as virology and immunology that are perceived as more prestigious by policymakers and senior managers. The built-in bias in these "excellence" schemes can thus lead to biases in resource allocation (Shibayama \& Baba, 2015) In a sense, the narrative of "excellence", both on a national or international level, supplants some of the discussion of research as a social need (Bozeman and Sarewitz, 2011). Furthermore, research funding is seen to favour projects which are deemed "innovative" or "ground-breaking", rather than some of the more routine work associated with tackling disease (see Yaqub \& Nightingale (2012) on the polio vaccine). According to one participant:

For me, the operational research is much more what translates into how to manage the disease, how to translate it into policies. What I see is that research institutions and most of the research funding goes into much more this more fundamental research, looking at the virus, looking at the production of the vaccine. There's not much funding looking more to the operational side. (senior scientist and advisor at an international organization)

More generally, interviewees saw funding mechanisms as being outside their sphere of influence, but as a determining factor for how research options are not only promoted, but also defined. At the very least, this points to a lack of transparency in terms of what types of projects are being funded, or potentially to a lack of engagement of stakeholders in setting priorities (Tallon, Chard, \& Dieppe, 2000).

Scholarly journals play a complex role in promoting, diffusing and, perhaps most importantly, rewarding various strands of avian influenza research. Many participants recognized that an a priori vision of the research landscape (such as the basis for the maps presented in Figures 6-10) are inherently skewed to reflect only research that is published in scholarly journals, thus excluding grey literature as well as correspondence or scientific advice to government that may or may not be made public. Pressure to publish is also perceived to have more subtle effects in terms of the priorities of researchers.

You have certain articles that have been published, but the translation [to application or policy] of that is missing. Or for example, one of my big criticisms to many research projects, they go to villages. They do research in remote areas. But never this information is fed back to the villages themselves. You know? They are kind of so fixed to get it 
published, but the community where the research was done never has any benefits of that research.

Both science policy scholars and researchers indicated-albeit in different terms-that journals contribute to shape the overall balance of power between disciplines and among different specialties within the same discipline. In many cases these biases in power "distort" the research enterprise, pushing it towards certain areas (van Eck, Waltman, van Raan, Klautz, \& Peul, 2013; Young, loannidis, \& Al-Ubaydli, 2008). For example, standards on sample sizes and statistical tests have a significant impact on fields such as epidemiology, defining what can be published and where. Additionally, the waxing and waning in popularity of different techniques for developing vaccines (e.g., the use of adjuvants), particularly where there are high-profile successes or failures reported (Miller et al., 2013; Reed, Bertholet, Coler, \& Friede, 2009; Shoenfeld \& Agmon-Levin, 2011), can have a very fast and significant impact on what can and cannot be published in journals seen as prestigious.

Most importantly, this perceived "distortion" is related to the journal hierarchy in science. Those closely connected to research recounted specific examples of certain scientific practices being more recognized than others. For example, Figure 9 below shows the epistemic areas where so-called "high-impact" journals (Nature, Science, PNAS, Cell, BMJ and The Lancet) publish most: the figure clearly shows that these publications fall mainly in the biomedical areas - and underrepresent field studies and epidemiology, among others. Indeed, the ability of an article to receive high numbers of citations is larger in certain fields than in others (e.g., comparing biomedicine with social science). For example, according to one researcher:

Well, it's certainly something published new in a high impact journal, like you see some of them here that are considered high impact. So, something appealing there on influenza, yeah, you would immediately have people that try to mimic - to repeat it or to maybe twist the research line in that direction.

The case of perceived risks from dual-use research illustrates the various levels on which publishing pressures can operate. In this case, participants cited both a positive and negative impact of the controversy over dual-use research on publishing results from these lines of research (Edwards, Revill \& Bezuidenhout, 2014). While existing or potential publishing restrictions may have discouraged some researchers from pursuing these lines of research, the visibility (as measured both by citations and other metrics such as tweets) received by those studies may also have made them attractive to top journals. Overall, most participants suggest that academic incentive structures may have the most significant impact on fostering a perceived mismatch between avian influenza research and desired outcomes. 

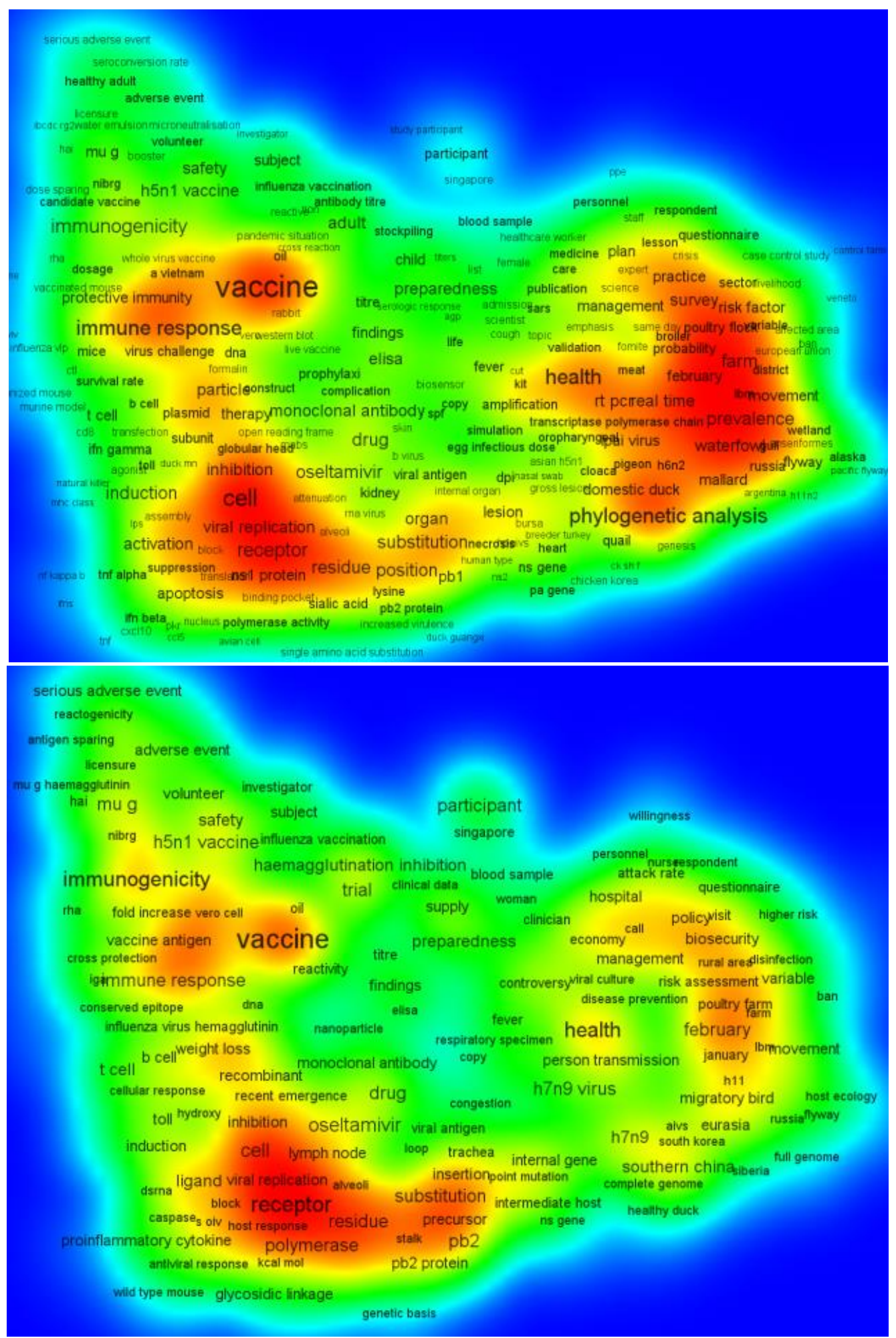

Figure 9: Publication density map of the avian influenza research landscape (2004-2013), showing which terms occur most often (in red). Top: the same original "basemap" of Figure 6 (without the coloured clusters, using instead a density visualization) showing where the bulk of publications lie. Bottom: the map corresponding only to terms found in highestimpact journals (specifically, we have chosen Nature, Lancet, Science, British Medical Journal, Cell and the Proceedings of the National Academy of Sciences of the USA). Comparing the two, we see that "high-impact" publications tend to more heavily concentrated around basic virology research (bottom left) and much less around epidemiology and public health. 


\subsubsection{Missions of governmental organizations}

Avian influenza research takes place in a variety of settings associated with the different approaches (statistical analysis and modelling, "wet" laboratories, veterinary fieldwork, etc.), as well organizational contexts (government, private sector, non-governmental organization, or university). Naturally, scientific priorities vary among performing and funding institutions with different organizational missions, be they focused on regulation, communicating risk, informing national policy, informing clinical practice or producing "excellent" science, for instance, as in the case of many universities. We found that participants were often able to speak to "organizational pressures" on research in a general manner and, more importantly, relate their own organizational context to their roles as performers, funders or users of avian influenza research. Many participants pitted organizational pressures against stronger ones related to publishing or academic funding. For example, according to a scientist at a national health agency:

Yes, more funding [for this type of research is needed] because these are routine surveillance activities. These are not research. It's different because I need more money to have people working in routine surveillance activity in order to let me work on the research activity, publications.

Through our interviews, we identified three main organizational thrusts: policy development (namely, national or international regulation, prevention or coordination endeavours), knowledge production (often described as "pure" research) and clinical applications. These can be associated with government, universities (and similar "pure" research organizations), and hospitals (and other health-oriented institutions). Many organizations, particularly those associated with government or hospital settings, have other dominant priorities, thus research as an activity in itself might not be the main focus. The research they do perform tends to be targeted to specific clinical or policy-oriented applications, as illustrated in Figure 10. On the other hand, university researchers dominate the overall landscape (e.g., Figure 6) and select topics based on strategies to maximize funding (Laudel, 2006). Many stakeholders felt that the mandates of these governmental organizations were more connected to concrete risk mitigation strategies and thus, in some cases, helped shape the agenda of research according to specific societal outcomes. 


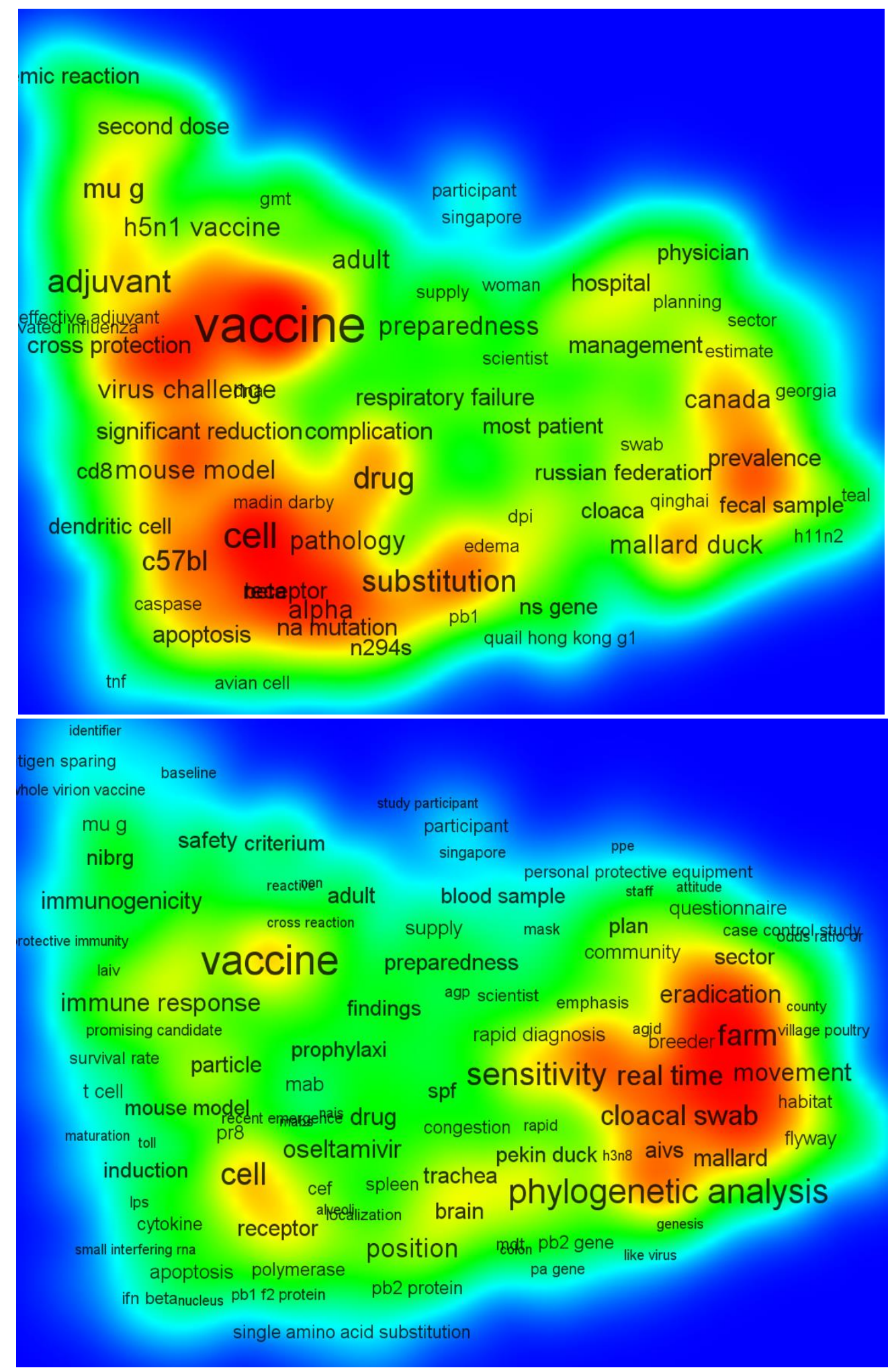

Figure 10. Similar to Figure 9, density maps of overlays of a subset of research performed in hospital settings (top) and government settings (bottom). The articles for hospital settings were selected by isolating authors' abbreviated addresses (in Web of Science format) containing the strings "hosp" or "clin" (for hospitals), and "minist", "natl" or "agcy" (for government). Those containing elements of both sets, or containing the string "univ" were excluded. 
However, many participants also indicated that the disproportionate influence of international organizations such as the WHO in driving both control policies and research policies meant that there was less diversity in research and too much focus on human health, for example (as opposed to animals or livelihoods). This has already been documented in terms of the dominant role of the WHO at the centre not only of international response narratives, but also research priorities (Scoones, 2010, Chapter 1). Some view this as governance issues or questions of "organizational culture" which can be more or less serious and sometimes related to the indirect influence of the private sector. For example:

[Fundamental virology researchers] have very good - historically very good connections with the public health authorities through the WHO; and also with - because the WHO meets every - two times a year to decide on the vaccine - vaccine composition. So, that means meeting scientists and the companies, so there is kind of - there's not a conflict of interest, but there is mutual interest to - to listen to each other's arguments. [...] Now WHO is very open about this because this is always published, what is then talked about. (senior university researcher)

Other stakeholders highlighted the fact that different organizational missions hinder collaboration and sharing of information, which is central to tackling avian influenza as a global "grand challenge". For example, people working in hospitals or in the field are sometimes less interested in collecting high-quality samples that can then be used in a laboratory setting. Similarly, those working for national governments may be reluctant to share information or even virus samples. This can be because data at a national level can point to deficiencies in preparedness and prevention, or because there is concern over their access or ability to use downstream outputs, such as vaccine use or production in the case in Indonesia (Fidler, 2010). Overall, however, major organizational pressures are not viewed as accentuating the perceived divide between research and societal needs, possibly because their missions are often explicitly stated as addressing societal needs. Nevertheless, the concentration of political or technocratic power in these organisations can be problematic as it may reduce diversity both in control/policy measures and in research.

\section{Discussion and conclusion}

This paper has presented an empirical investigation on priority setting in influenza research. Starting from the context of a contested and controversial research enterprise, we first explored the dominant narratives of avian flu. These are related both to strategies for the mitigation of a future global pandemic and to the existing research landscape as a set of "options" that help inform mitigation strategies. We found that different experts (policymakers, virologists, epidemiologists, etc.) have different perspectives on what should be done. We have observed a generalized difficulty of relating research agendas (science supply) with outcomes relevant for tacking influenza (societal demands). We have then concentrated our efforts on understanding what drives the research agenda and sets research priorities. To do so, we focused on the institutional pressures reported by a range of stakeholders and researchers.

Our mixed-method (quantitative and qualitative) analysis has provided insights into the dynamics of research "supply" and "demand", that have defined the rapid growth in avian influenza research over the last decade. In particular, we have discussed various ways in which influenza is framed as a mitigation of 
the risk of a global pandemic, based on a range of social and technological interventions. We have also revealed how research options can be explored in distinct ways, as choices among dominant disciplines or between lab and fieldwork, for example. Human, as opposed to animal research is often seen as being at the forefront, just as research geared towards rapid technological advances supersedes incremental, often local, improvements to surveillance and detection. "Ground-breaking" laboratory work or largescale models of pandemic spread are often perceived to dominate the research landscape at the expense of "descriptive" field studies and publically-funded clinical trials. We can also cite other issues specific to avian influenza, such as the movement of birds across national boundaries, or the modes of coexistence of humans and birds as livestock within certain communities, which would require a more holistic approach to mitigating the risk of a pandemic. While we found clearly-defined "camps" between epidemiologists and virologists or between policymakers and scientists, for example, none of these divisions explained the diversity of views on what the priorities are - suggesting that personal, value-laden views play an important role.

The interviews and the bibliometric analysis shed light on how public avian influenza research is currently being driven by private sector investment (e.g., towards the development of vaccines and antivirals), by "excellence"-oriented academic drivers (e.g., broadly towards basic biomedical research) and the mandates of large national and international organizations (especially those focused on human health). All three of these institutions have been found to explicitly and implicitly define what researchers choose to focus on to advance their work within their organization or within the scientific community.

While some polarization of views of the positive or negative influence of the private sector is nothing surprising, a more notable result is the degree to which public-especially "academic"-research institutions (or "intra-scientific factors") appear to foster a disconnect between research and outcomes (Luukkonen and Thomas, 2015). This represents a potential "relevance gap" in the research agenda (Nightingale \& Scott, 2007). Our analysis points to systematic biases in the way public sector research is managed. These biases reinforce existing research options and the pursuit of an unsituated or decontextualized notion of "excellence" (Figure 9). Universities, as dominant institutions in the research landscape are more driven by a pursuit of "excellence", the key to increased funding, among other rewards. Such an approach is neither neutral nor attentive of the diverse concerns of stakeholders. Governmental institutes and hospitals tend to drive research according to more demand-defined objectives (Figure 10).

This study may have broader relevance for managing research in terms of "grand societal challenges" or for how science policy responds to "shocks" with a rapid influx of research resources. It suggests that for a given issue, a first step in priority setting is to acknowledge the existence of a broad range of possible relevant outcomes and many possible research options for achieving them. One can conceive of research portfolio management informed by diverging worldviews. The management should not rely only on preexisting research categories or "labels", but rather map new research options and diverse potential outcomes. Most importantly, in addition to resource allocation decisions, designs for governance of research should explicitly take into account the institutional pressures in place that shape research agendas and their uptake. 


\section{Acknowledgements}

We thank Jordi Molas-Gallart, Jochen Gläser, Grit Laudel, Andy Stirling and Richard Woolley for fruitful discussions. We acknowledge support from the FP7 EU Marie Curie Integration Grant to IR (MapRePort).

\section{References}

Abeysinghe, S., \& White, K. (2011). The avian influenza pandemic: Discourses of risk, contagion and preparation in Australia. Health, Risk \& Society, 13(4), 311-326.

Agarwal, P., \& Searls, D. B. (2009). Can literature analysis identify innovation drivers in drug discovery? Nature Reviews. Drug Discovery, 8(11), 865-78.

Barrett, R., \& Brown, P. J. (2008). Stigma in the time of influenza: social and institutional responses to pandemic emergencies. The Journal of Infectious Diseases, 197 Suppl (Suppl 1), S34-S7.

Becher, T., \& Trowler, P. (2001). Academic Tribes and Territories. Philadelphia: Society for Research into Higher Education \& Open University Press.

Benner, M., \& Sandström, U. (2000). Institutionalizing the triple helix: research funding and norms in the academic system. Research Policy.

Bourdieu, P. (1976). Le champ scientifique. Actes de La Recherche En Sciences Sociales, 2(2), 88-104.

Butler, L. (2003). Explaining Australia's increased share of ISI publications - the effects of a funding formula based on publication counts. Research Policy, 32(1), 143-155.

Calvert, J. (2006). What's Special about Basic Research? Science, Technology \& Human Values, 31(2), 199-220.

Chien, Y.-J. (2013). Constructing Knowledge and Policies on Avian Influenza: How Do International Organizations Craft Global Models. University of MInnesota.

Dawood, F. S., Iuliano, A. D., Reed, C., Meltzer, M. I., Shay, D. K., Cheng, P.-Y., ... Widdowson, M.-A. (2012). Estimated global mortality associated with the first 12 months of 2009 pandemic influenza A H1N1 virus circulation: a modelling study. The Lancet Infectious Diseases, 12(9), 687-695.

Edwards, B., Revill, J., \& Bezuidenhout, L. (2014). From Cases to Capacity? A Critical Reflection on the Role of "Ethical Dilemmas" in the Development of Dual-Use Governance. Science and Engineering Ethics, 20(2), 571-582.

Evans, J. a, Shim, J.-M., \& loannidis, J. P. a. (2014). Attention to local health burden and the global disparity of health research. PloS One, 9(4), e90147. 
Ferguson, N. M., Cummings, D. a T., Fraser, C., Cajka, J. C., Cooley, P. C., \& Burke, D. S. (2006). Strategies for mitigating an influenza pandemic. Nature, 442(7101), 448-452.

Fidler, D. P. (2010). Negotiating equitable access to influenza vaccines: global health diplomacy and the controversies surrounding avian influenza H5N1 and pandemic influenza H1N1. PLoS Medicine, 7(5), e1000247.

Foray, D., Mowery, D. C., \& Nelson, R. R. (2012). Public R\&D and social challenges: What lessons from mission R\&D programs? Research Policy, 41(10), 1697-1702. doi:10.1016/j.respol.2012.07.011

Forster, P. (2012). To Pandemic or Not? Reconfiguring Global Responses to Influenza. Brighton.

Friede, M., Palkonyay, L., Alfonso, C., Pervikov, Y., Torelli, G., Wood, D., \& Kieny, M. P. (2011). WHO initiative to increase global and equitable access to influenza vaccine in the event of a pandemic: supporting developing country production capacity through technology transfer. Vaccine, 29 Suppl $1, \mathrm{~A} 2-7$.

Global Health Watch. (2011). Global Health Watch 3: An alterantive World Health Report. London: Zed Books.

Goldfarb, B. (2008). The effect of government contracting on academic research: Does the source of funding affect scientific output? Research Policy, 37(1), 41-58.

Gulbrandsen, M., \& Smeby, J.-C. (2005). Industry funding and university professors' research performance. Research Policy, 34(6), 932-950.

Head, M. G., Fitchett, J. R., Cooke, M. K., Wurie, F. B., Hayward, a. C., Lipman, M. C., \& Atun, R. (2014). Investments in respiratory infectious disease research 1997-2010: a systematic analysis of UK funding. BMJ Open, 4, e004600-e004600.

Heinze, T., Shapira, P., Rogers, J. D., \& Senker, J. M. (2009). Organizational and institutional influences on creativity in scientific research. Research Policy, 38(4), 610-623.

Herfst, S., Schrauwen, E. J. a, Linster, M., Chutinimitkul, S., de Wit, E., Munster, V. J., ... Fouchier, R. a M. (2012). Airborne transmission of influenza A/H5N1 virus between ferrets. Science (New York, N.Y.), 336(6088), 1534-41.

Jasanoff, S. (Ed.). (2004). States of Knowledge: the co-production of science and social order. London: Routledge.

Kasperson, R. E., Renn, O., Slovic, P., Brown, H. S., Emel, J., Goble, R., ... Ratick, S. (1988). The Social Amplification of Risk: A Conceptual Framework. Risk Analysis, 8(2), 177-187.

King, N. B. (2002). Security, Disease, Commerce: Ideologies of Postcolonial Global Health. Social Studies of Science, 32(5-6), 763-789. 
Kreimer, P., \& Zabala, J. P. (2007). Chagas Disease in Argentina: Reciprocal Construction of Social and Scientific Problems. Science Technology \& Society, 12(1), 49-72.

Laudel, G. (2005). Is external research funding a valid indicator for research performance? Research Evaluation, 14(1), 27-34.

Laudel, G. (2006). The art of getting funded: How scientists adapt to their funding conditions. Science and Public Policy , 33 (7), 489-504.

Laudel, G., \& Gläser, J. (2014). Beyond breakthrough research: Epistemic properties of research and their consequences for research funding. Research Policy, 43(7), 1204-1216.

Lindenbaum, S. (2001). Kuru, prions, and human affairs: Thinking about epidemics. Annual Review of Anthropology, 30, 365-385.

Miller, E., Andrews, N., Stellitano, L., Stowe, J., Winstone, A. M., Shneerson, J., \& Verity, C. (2013). Risk of narcolepsy in children and young people receiving AS03 adjuvanted pandemic A/H1N1 2009 influenza vaccine: retrospective analysis. BMJ (Clinical Research Ed.), 346(February), f794.

Nightingale, P., \& Scott, A. (2007). Peer review and the relevance gap: Ten suggestions for policymakers. Science and Public Policy, 34 (8), 543-553.

Payne, D. (2012). Tamiflu: the battle for secret drug data. BMJ, 345(oct29 2), e7303-e7303.

Quinn, T. (2008). Flu: A Social History of Influenza. London: New Holland Publishers.

Reed, S. G., Bertholet, S., Coler, R. N., \& Friede, M. (2009). New horizons in adjuvants for vaccine development. Trends in Immunology, 30(1), 23-32.

Rosenfield, P. L. (1992). The potential of transdisciplinary research for sustaining and extending linkages between the health and social sciences. Social Science \& Medicine, 35(11), 1343-1357.

Rotolo, D., \& Leydesdorff, L. (2015). Matching Medline/PubMed data with Web of Science: A routine in $\mathrm{R}$ language. Journal of the Association for Information Science and Technology.

Sarewitz, D., \& Pielke, R. a. (2007). The neglected heart of science policy: reconciling supply of and demand for science. Environmental Science \& Policy, 10(1), 5-16.

Scoones, I. (Ed.). (2010). Avian Influenza: Science, Policy and Politics. London: Routledge.

Shibayama, S., \& Baba, Y. (2015). Impact-Oriented Science Policies and Scientific Publication Practices: The Case of Life Sciences in Japan. Research Policy, 44(4), 936-950.

Shoenfeld, Y., \& Agmon-Levin, N. (2011). "ASIA" - autoimmune/inflammatory syndrome induced by adjuvants. Journal of Autoimmunity, 36(1), 4-8.

Slovic, P. (1993). Perceived Risk, Trust, and Democracy. Risk Analysis, 13(6), 675-682. 
Stirling, A. (2007a). A general framework for analysing diversity in science, technology and society.

Stirling, A. (2007b). Risk, precaution and science: towards a more constructive policy debate. EMBO Reports, 8(4), 309-315.

Suk, J. E., Bartels, C., Broberg, E., Struelens, M. J., \& Ozin, A. J. (2014). Dual-use research debates and public health: better integration would do no harm. Frontiers in Public Health, 2(September), 114.

Tallon, D., Chard, J., \& Dieppe, P. (2000). Relation between agendas of the research community and the research consumer. The Lancet, 355(9220), 2037-2040.

Van Eck, N. J., \& Waltman, L. (2010). Software survey: VOSviewer, a computer program for bibliometric mapping. Scientometrics, 84(2), 523-538.

Van Eck, N. J., Waltman, L., van Raan, A. F. J., Klautz, R. J. M., \& Peul, W. C. (2013). Citation analysis may severely underestimate the impact of clinical research as compared to basic research. PloS One, $8(4)$, e62395.

Waaijer, C. J. F., van Bochove, C. a, \& van Eck, N. J. (2011). On the map: Nature and Science editorials. Scientometrics, 86(1), 99-112.

Waltman, L., Eck, N. J. Van, \& Noyons, E. C. M. (2009). A unified approach to mapping and clustering of bibliometric networks, 1-11.

Yaqub, O., \& Nightingale, P. (2012). Vaccine innovation, translational research and the management of knowledge accumulation. Social Science and Medicine, 75(12), 2143-2150.

Young, N. S., loannidis, J. P. a, \& Al-Ubaydli, O. (2008). Why current publication practices may distort science. PLoS Medicine, 5(10), e201. 